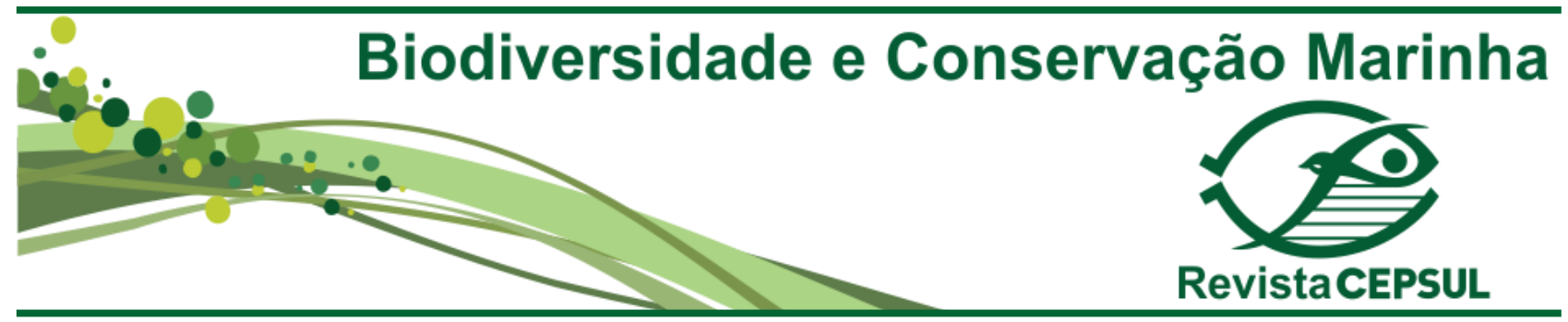

ARTIGO

\title{
A contribuição da gestão da informação para o uso dos recursos pesqueiros no Brasil.
}

\author{
CHARLES RODRIGUES ${ }^{1}$
} 1 Doutorando em Ciência da Informação pelo Programa de Pós-graduação em Ciência da Informação da Universidade Federal de
Santa Catarina UFSC, falecomcharles@yahoo.com.br.

Resumo. Vivencia-se um período de crescente fluxo de informação entre as nações, o que é a base das relações de poder político, econômico, social, científico, tecnológico e comercial. Uma das formas de exercer esse poder é conhecer as fontes de informação. Para isso, é necessário organizá-las, tratá-las e analisá-las dentro de um contexto a fim de utilizá-las da forma mais apropriada para a tomada de decisão. Neste estudo, visa-se refletir e discutir sobre a contribuição da gestão da informação para o uso dos recursos pesqueiros no Brasil, entrelaçando o processo de uso e o compartilhamento das informações. Quanto à metodologia, trata-se de uma pesquisa bibliográfica, documental e exploratória, de método qualitativo. O texto se organiza em cinco partes: a) a introdução, em que são apresentados os objetivos e a problemática de pesquisa; b) a metodologia; c) a contextualização da pesca na sociedade da informação; d) a apresentação dos conceitos relacionados à gestão, ao uso e ao compartilhamento da informação; e e) a discussão e as considerações finais, em que se apresenta um modelo de gestão da informação para o uso dos recursos pesqueiros, estruturado em forma de processos sequenciais e interativos, composto por quatro etapas. O resultado esperado é um processo informacional que contribua para a elaboração, a implementação e o controle de ações, para o monitoramento do ambiente interno e externo e para as tomadas de decisão, proporcionando, assim, uma gestão mais adequada dos recursos pesqueiros no Brasil.

Palavras-chave: Gestão da informação; Uso da informação; Compartilhamento da informação; Gerenciamento dos recursos pesqueiros.

\begin{abstract}
The information management contribution to the use of fisheries resources in Brazil. Experiences a period of increasing the flow of information between nations, which is the basis of relations of political power, economic, social, scientific, technological and commercial. One way of exercising power is to know the sources of information. Therefore, it is necessary to organize them, treat them and analyze them in context, so you can use it in the most appropriate way for decision making. This study aims to reflect and discuss on the information of the management's contribution for the use of fisheries resources in Brazil, linking the process of use and sharing of information. As methodology it is a bibliographical research, documentary and exploratory, qualitative method. It is organized
\end{abstract}


into five parts: a) introduction, which outlines the research problem and objectives; b) methodology; c) fishing is contextualized in the information society; d) are exposed the concepts related to the management, use and sharing of information; and e) the discussion and considerations, in which presented an information management model for the use of fisheries resources, structured in the form of sequential and interactive processes, consisting of four steps. The expected result is an informational process that contributes to the development, implementation and control actions for monitoring the internal and external environment and decision-making, thus providing better management of fishing resources in Brazil.

Keywords: Information Management; Use of the Information; Information sharing; Fishery Management.

\section{Introdução}

As transformações pelas quais vem passando a sociedade do século XXI, como consequência da dinâmica da globalização, podem ser analisadas sob diversos aspectos, especialmente perante a complexidade e multiplicidade das relações políticas, sociais e econômicas. Vivencia-se um período de crescente fluxo de informação entre as nações, o que é a base das relações de poder político, econômico, social, científico, tecnológico e comercial, e uma das formas de exercê-lo é conhecer as fontes de informação. Para isso, é necessário organizálas, tratá-las e analisá-las dentro de um contexto a fim de que se possa utilizá-las da forma mais apropriada para a tomada de decisão em relação às questões como: desenvolvimento sustentável, econômico, social, melhorias educacionais, degradação ambiental dentre outras.

Embora exista o Sistema Nacional de Informação da Pesca e Aquicultura (SINPESQ) vinculado ao Ministério da Pesca e Aquicultura (MPA), este no momento (setembro de 2015) encontra-se com links importantes ainda em construção, ou seja, sem fornecimento de informações e conteúdos. Outro aspecto relevante é a pouca usabilidade da interface do site (falta de clareza, concisão e mecanismo de busca de informação). Outro entrave é a necessidade de criação de login para que se possam acessar determinadas informações.

Assim, entende-se que é necessário ponderar sobre maneiras de melhorar os siste- mas de informação já existentes, de modo que se possa subsidiar a gestão dos recursos pesqueiros no Brasil.

Neste estudo, seguindo a premissa de que "[...] ter informações disponíveis é fundamental, mas isso por si só não basta, é necessário compreendê-las e saber usá-las, incorporando-as ao processo de gestão da organização" (Costa, 2003), estabelece-se a problemática de pesquisa na tentativa de responder a seguinte questão: como o acesso, o uso e o compartilhamento de informação podem contribuir para o uso dos recursos pesqueiros no Brasil? Dessa forma, neste estudo, visa-se refletir e discutir sobre a contribuição da gestão da informação para o uso dos recursos pesqueiros no Brasil, entrelaçando o processo de uso e o compartilhamento das informações.

\section{Procedimentos Metodológicos}

Este estudo foi realizado por meio de pesquisa bibliográfica, documental e exploratória, numa abordagem qualitativa, cujo objetivo foi o de sustentar a fundamentação conceitual e contribuir com as discussões sobre o objeto de pesquisa, permitindo, assim, validar cientificamente a pesquisa.

Para Marconi \& Lakatos (2010, p. 142), “[...] a pesquisa bibliográfica é um apanhado geral sobre os principais trabalhos já realizados, revestidos de importância, por 
serem capazes de fornecer dados atuais e relevantes relacionados com o tema". Os autores ainda afirmam que, antes de iniciar as pesquisas, o primeiro passo é a análise detalhada de todas as fontes documentais que possam servir de indícios à investigação.

$\mathrm{Na}$ pesquisa exploratória, buscaram-se fontes de informações nas bases de dados da Coordenação de Aperfeiçoamento de Pessoal de Nível Superior (CAPES) e na Web of Science sobre as teorias e os conceitos relacionados à temática em estudo. O método qualitativo contribuiu para melhor compreender $\mathrm{o}$ fenômeno enquanto processo social e permitiu, com isso, a análise sistêmica de seu contexto.

\section{A pesca e a sociedade da informação}

A sociedade da informação se desenvolve em torno das implicações geopolíticas que, segundo Mattelart (2002), tem como pivô o paradigma tecnoinformacional, "[...] que tem como função garantir o rearranjo geoeconômico do planeta em torno dos valores da democracia de mercado e em um mundo unipolar". Nesta perspectiva, a intencionalidade é moldar a diversidade cultural, em torno dos interesses, ideias e pensamentos dos modos de produção dominantes. $\mathrm{E}$ isto ocorre de forma processual e em longo prazo.

E os avanços das tecnologias de informação e comunicação possibilitaram transformações nos modelos de comportamento social; desse modo, segundo Castells (1999), desenvolveu-se o informacionalismo, que

[...] baseia-se na tecnologia do conhecimento e informação, há uma íntima ligação entre cultura e forças produtivas e entre espírito e matéria, no modo de desenvolvimento informacional. Portanto, devemos esperar o surgimento de novas formas históricas de interação, controle e transformação social.
No que se refere ao ambiente informacional, Levy (2001) reflete sobre a planetarização sustentada por conexões enraizadas em todas as esferas das relações humanas. Argumenta que, nesse ambiente, não haverá mais espaços para pessoas tecnologicamente analfabetas ou que não tenham um mínimo de conhecimento acerca das tecnologias. Para conviver e participar ativamente, será cobrado um envolvimento maior de todos, e a capacidade intelectual individual será um diferencial social ainda maior.

Neste contexto, torna-se ainda mais importante a necessidade de criação de políticas públicas para mitigar o status quos das pessoas que não se "enquadram" nesta perspectiva. Pois de uma medida de maior ou menor grau elas estarão vivendo neste ambiente.

Segundo Kerr Pinheiro (2010), o empirismo e as práticas advindas das inovações técnicas mostram os diferentes atores da sociedade da informação no processo de construção do conhecimento. Existe um propósito no fato de as inovações políticas os capturar. Assim, a adaptação, a reinterpretação ou a substituição de certas leis ou regras, em nível micro, obrigam a se pensar a política de informação a partir da análise dessas leis e regras distribuídas ao longo do ciclo de criação e de tratamento dos fluxos e de utilização da informação a ser repensada nos contextos, único lócus possível de precisão do conceito de informação.

Todavia, importante destacar que o efeito sucessivo dessas inovações não ocorre de forma linear e equânime em todos os setores da sociedade da informação.

No contexto da sociedade da informação, percebe-se que o processo de busca por informação e conhecimento que caracteriza a função da produção tecnológica tende a se expandir com a utilização de inovações e com o desenvolvimento mais acelerado de novos produtos e serviços baseados na informação. E a pesca se desenvolve nesse ambiente.

De um modo geral, os recursos pes- 
queiros marinhos ocorrem em um ambiente contínuo, sem barreiras ou fronteiras. Assim, as espécies, ao migrarem de um lugar ao outro, sofrem ações de vários atores locais, o que provoca a necessidade de uma ação global para o ordenamento e a conservação, conforme podem ser vistos nos tratados e convenções coordenados pela Food and Agriculture Organization of the United Nations (FAO). Além disso, a pesca está suscetível às interferências e mudanças sociais, políticas, tecnológicas, científicas e econômicas que a sociedade sofre historicamente.

Nas comunidades de pescadores houve alterações estruturais profundas nas formas de organização social da produção, as quais alteraram e ainda alteram toda a estrutura familiar e o corpo social em que vivem. Esse processo ocorre por introdução de conceitos e ideologias que não estavam presentes na forma de essas comunidades "verem o mundo". No caso, conceitos como globalização, mercado (pescado como mercadoria), consumo, novas tecnologias e capitalismo trouxeram transformações estruturais e sociais para os pescadores.

Essas modificações começaram a ocorrer com o capitalismo da pesca que levaram a introdução de novas tecnologias pesqueiras que transformaram os modos de produção. Vale ressaltar que o capitalismo e a tecnologia são aspectos da complexidade da sociologia humana, das interações das relações e dos símbolos culturais que os seres humanos criam e usam para organizar a sociedade.

Em todas as sociedades que maximizaram a produção e a renda, como em partes das comunidades de pescadores, o desenvolvimento social está sustentado na visão mercantilista e no determinismo tecnológico, os quais são demarcados por estruturas históricas de produção, experiência e poder. De acordo com Castells (1999),

Produção é ação da humanidade sobre a matéria (natureza) para apropriar-se dela e transformá-la em seu benefício, obtendo um produto, consumido (de forma irregular) parte dele e acumulando o excedente para investimento conforme os vários objetivos socialmente determinados. Experiência é ação dos sujeitos humanos sobre si mesmos, determinada pela interação entre as identidades biológicas e culturais desses sujeitos em relação a seus ambientes sociais e naturais. É construída pela eterna busca da satisfação das necessidades e desejos humanos. Poder é aquela relação entre os sujeitos humanos que, com base na produção e na experiência, impõe a vontade de alguns sobre os outros pelo emprego potencial ou real de violência física ou simbólica. As instituições sociais são constituídas para impor o cumprimento das relações de poder existentes em cada período histórico, inclusive os controles, limites e contratos sociais na luta pelo poder.

Essa relação entre produção, experiência e poder também ocorreu no processo de transformação das comunidades de pescadores e, então, afetou as estruturas das formas de organização social da produção pesqueira no Brasil.

O processo de introdução do capitalismo na pesca se realizou concomitantemente ao crescimento da demanda por produtos da pesca, à expansão das frotas industriais e à criação de políticas que favoreceram a captura em larga escala, o que alterou visivelmente a estrutura da pesca. Nesse contexto, uma das consequências da incorporação das chamadas pescas tradicionais artesanais ao mercado foi a especialização numa só atividade e o abandono de outras.

No presente modo de produção, passase por um dilema: a necessidade de conjugar, de forma equânime, a produtividade, a geração de emprego, a otimização dos processos, a rentabilidade organizacional, a inovação e a sustentabilidade ecológica. Por anos, o meio ambiente foi utilizado apenas como fornecedor 
de matéria-prima, sem existir a preocupação com o impacto no ecossistema deste modo de produzir. Em razão do esgotamento desse estoque natural e da demanda por novos produtos, provocada pelo aumento do mercado consumidor dessa matéria-prima, corre-se o risco de o ecossistema entrar em colapso. Por esse motivo, as empresas deveriam buscar o desenvolvimento de novos meios de produção que afetem ou impactem menos o meio ambiente.

Na seção seguinte, expõe-se como os conceitos relacionados à gestão, ao uso e ao compartilhamento da informação podem contribuir com ações mitigadoras para o setor pesqueiro diante desse cenário.

\section{Gestão, uso e compartilhamento da in- formação}

O estudo e a análise da gestão da informação do ambiente pesqueiro são importantes para entender como ocorre o processo de construção do conhecimento e, nesse ínterim, o das fontes de informação utilizadas, assim como das formas de uso e compartilhamento dessas fontes. São importantes, portanto, para conhecer quais os meios e por quais canais de comunicação esses conhecimentos são apresentados e como contribuem para a tomada de decisão.

Conceitualmente, Davenport et al. (2004) afirmam que a gestão da informação deve tratar de "como coletar, armazenar, consultar, distribuir e explorar a informação no interior das organizações e nas redes de fornecedores, clientes e outros parceiros".

Em se tratando do ambiente corporativo, Alvares et al. (2010) abordam a importância da informação na gestão empresarial, reconhecendo-a como elemento determinante não apenas no processo de criação do conhecimento, mas como elementochave para a competitividade. Dessa forma, estabelecem a gestão estratégica da informação com base em seis etapas do modelo de Tarapanoff (2001): (a) identificação de necessidades informacionais; (b) aquisição de informação, cujos requisitos são as necessidades da organização; (c) armazenamento; (d) desenvolvimento de produtos e serviços informacionais; (e) distribuição; e (f) uso efetivo.

Molina (2010), dissertando sobre a informação nas organizações, afirma que, além do valor monetário representado para uma determinada organização em relação à sua situação no mercado e sua competitividade, há também uma supervalorização do conhecimento gerado, visto ser este o insumo para a inovação.

Segundo Souza \& Duarte (2011), os modelos da gestão da informação têm sido utilizados com frequência como parâmetros de qualidade na informação que circula dentro dos ambientes organizacionais. As autoras propõem um modelo de gestão da informação composto de 15 dimensões que, agrupadas, formam o corpus representado na Figura 1, referente ao caminho percorrido pela informação, desde o momento de sua concepção até o estágio final destinado ao usuário.

Souza \& Duarte (2011) comentam que as dimensões desse modelo de gestão da informação seguem uma sequência lógica baseada nas etapas percorridas pelo usuário até que ele, finalmente, consiga utilizar a informação obtida.

Importante destacar que há um componente político muito forte em cada uma dessas etapas, direcionado à intenção política de quem utilizará as informações. Quem determina que informações serão necessárias, quem seleciona, quem promove e de que forma promove o acesso à informação?

Os valores, orientações políticas, formas de organização e nível de conhecimento de quem está direcionando esse processo é determinante para o uso da informação. Informação não é a 
verdade, é o produto de uma estrutura política de determinação de necessidades, seleção e disponibilização da mesma. Por isso é necessário que estes processos sejam demandados pela sociedade de forma legítima, tratados de forma ética, transparente e disponibilizados de forma abrangente, contribuindo para uma gestão da informação com controle social.

Desse modo, o caminho feito pela informação, da fonte até o receptor, passa pelas seguintes etapas: (a) a determinação de necessidades de informação, o que envolve a busca, a coleta e a análise da informação; (b) a seleção da informação, o que abrange sua organização, seu armazenamento e sua recuperação; (c) o acesso à informação, o que abarca o desenvolvimento de produtos, o incremento de serviços e o compartilhamento, a disseminação e a utilização da informação.

Nessa exposição conceitual inicial, a intenção foi a de explicar as etapas que compreendem o processo de gerenciamento da in-

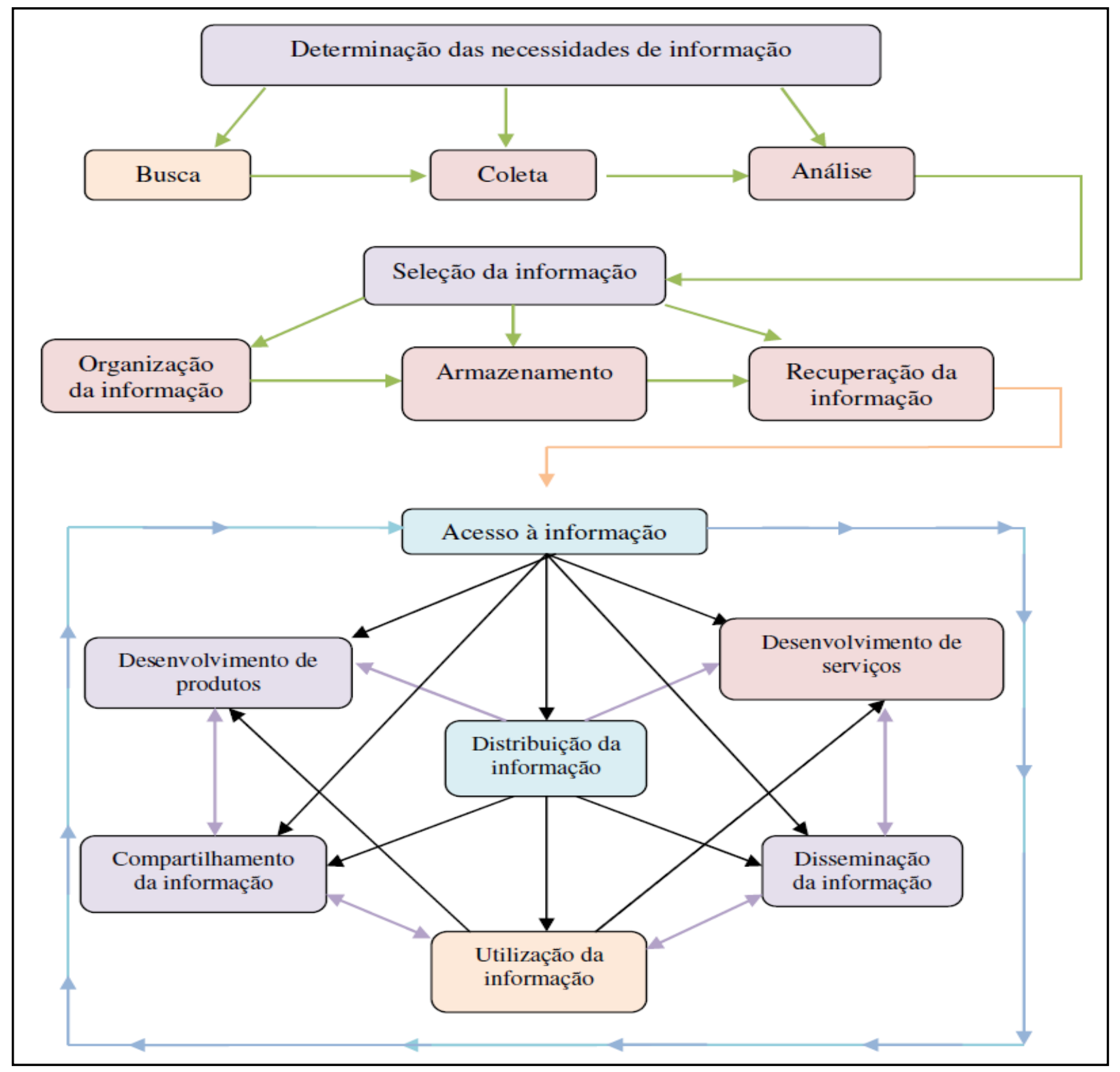

Figura 1. Diagrama do modelo de gestão da informação no ENANCIB.

Fonte: Souza \& Duarte (2011). 
formação, a fim de sustentar as demais fases deste estudo.

\section{Uso da informação}

Para Castells (1999), a atual revolução tecnológica não é a centralidade de conhecimento e informação, mas a aplicação desses conhecimentos e dessa informação para a geração de conhecimento e de dispositivos de processamento/comunicação da informação, em um ciclo de retroalimentação cumulativo entre a inovação e seu uso.

Nessa perspectiva, Le Coadic (2004, p. 38) expõe que:

\begin{abstract}
[...] usar a informação é trabalhar com a matéria informação para obter um efeito que satisfaça a uma necessidade de informação. Utilizar um produto de informação é empregar tal objeto para obter, igualmente, um efeito que satisfaça uma necessidade de informação, que esse objeto subsista (fala-se então de utilização), modifique-se (uso) ou desapareça (consumo).
\end{abstract}

Sugahara \& Jannuzzi (2005), em uma pesquisa sobre a inovação tecnológica das empresas industriais brasileiras, verificaram que o desempenho inovador é influenciado, em especial, por fatores relacionados ao porte e ao tipo de atividade desenvolvida pela empresa. $\mathrm{Na}$ análise da intensidade de uso das fontes de informação, segundo o grau de importância conferido pelas empresas inovadoras brasileiras, reforçou-se a hipótese de que a habilidade para inovar é influenciada pela capacidade de as empresas absorverem e combinarem informações variadas de fontes internas e externas. Os resultados ainda sugerem que as indústrias inovadoras brasileiras, ao realizarem maior uso de informações provenientes de fontes associadas ao mercado, como fornecedores, clientes ou consumidores, estão mais propensas à promoção de inovações incrementais. Esse tipo de inovação resulta em boa parte de melhorias sugeridas pelos usuários de produtos ou serviços ofertados pelas indústrias.

Em um estudo sobre o processo decisório e informação, Leitão \& Nassif (2009) propõem uma relação entre decisão estratégica e informação na perspectiva do sensemaking organizacional. A teoria de sensemaking permite relacionar informação e processo decisório dentro da dimensão humana, em que a informação não é somente um conjunto de dados sobre os quais são feitas análises, mas sim é a matéria bruta de que se dispõe para construir a realidade. A partir do sentido atribuído à informação, constrói-se a decisão e, por consequência, a ação. Essa perspectiva pode esclarecer como lidar com a informação em contextos diversos e fazer compreender que os aspectos subjetivos influenciam o uso e a busca da informação. Além disso, essas questões subjetivas têm relações explícitas com os aspectos cognitivos, como as emoções, as crenças e os valores dos indivíduos e a forma como estes interagem com os eventos sociais.

Ademais, Leitão \& Nassif (2009) consideram que, para a tomada de decisões estratégicas, é preciso atribuir significado ao contexto organizacional, e esse processo de criação de significado está relacionado ao sensemaking organizacional. Então, é possível estabelecer uma relação entre contexto, significado, processo de formação de sentido das informações e tomada de decisões estratégicas nas organizações, conforme ilustra a Figura 2. Dessa forma, as decisões estratégicas são vistas como expressão do processo de formação de sentido das informações a partir do significado atribuído ao contexto. Em outras palavras, a realidade em torno da organização não está lá à espera de ser descoberta, pois é, na verdade, fruto de um processo de interpretação e criação de significados em uma relação dialética entre organização e ambiente competitivo. 


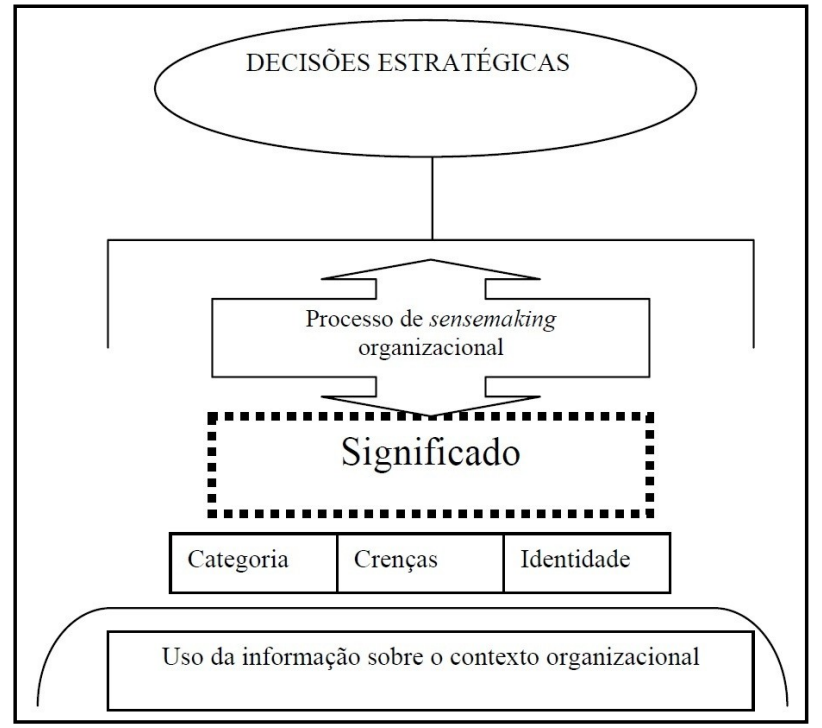

Figura 2. Relação entre uso da informação, sensemaking organizacional e decisões estratégicas.

Fonte: Leitão \& Nassif (2009).

Entretanto, quando se trata de informações direcionadas politicamente para o desenvolvimento organizacional de uma empresa ou corporação, esse pensamento faz todo o sentido. Porém, no caso de informações relativas a uso comum de territórios e de recursos pesqueiros, com impactos sociais e ambientais, o processo de interpretação e criação de significados precisa considerar um universo mais amplo de pessoas, organizações, instituições. Uma sociodiversidade que possa estar presente, de alguma forma, no processo de geração e uso da informação nesse contexto.

Outro aspecto que pode afetar o uso da informação é a cultura informacional, ou seja, os valores de informação, as normas e o comportamento da organização que determinam como as informações são usadas e aplicadas na organização (Abrahamson \& Goodman-Delahunty, 2013). Esses autores, baseando-se em estudos anteriores, mencionam que o comportamento de uso da informação está apoiado em seis estruturas: (1) a integridade da informação: uso de informações de forma confiável e íntegra em nível individual e organizacional; (2) a formalidade da informação: vontade de usar e confiar em informações institucionalizadas sobre as fontes informais; (3) o controle da informação: medida em que as informações sobre o desempenho são continuamente apresentadas às pessoas para gerenciar $\mathrm{e}$ monitorar seu desempenho; (4) a transparência da informação: clareza na elaboração de relatórios e apresentação de informações sobre falhas e erros; (5) a partilha de informação: disposição em fornecer informações às outras pessoas de forma adequada e colaborativa; e (6) a proatividade de informações: preocupação ativa para pensar sobre como obter e aplicar novas informações a fim de responder rapidamente e promover a inovação.

Destaca-se, ainda, que: o uso da informação alcança seu valor com a presença do usuário; a revolução tecnológica está na aplicação dos conhecimentos e da informação para a geração de conhecimento; a criação e o uso da informação envolvem a criação de significado, a construção do conhecimento e a tomada de decisão; e a cultura informacional precisa ser trabalhada em relação à produção, ao compartilhamento, ao uso e à apropriação da informação.

\section{Compartilhamento da informação}

É preciso compreender o compartilhamento da informação como um processo de comunicação, isto é, como um processo de emissão, transmissão e recepção de mensagens, não no sentido de partilha, não no sentido de cada um com sua parte. Compartilhar é ter a capacidade de trocar e/ou discutir ideias e pensamentos, é dialogar para encontrar melhores soluções para determinadas demandas organizacionais.

Nas etapas que compõem o processo de construção do conhecimento do acesso ao uso e ao compartilhamento, o ato de assimilar é mais um fato cognoscente que contribui de forma significativa nesse ciclo. Então, o processo de transferência da informação é necessário como agente mediador da produção de conhecimen- 
to. Assim, o conceito de assimilação da informação é considerado um processo de interação entre o indivíduo e uma determinada estrutura de informação que vem a gerar uma modificação em seu estado cognitivo e a produzir, assim, conhecimento que se relaciona, de modo correto, com a informação recebida. É um estágio qualitativamente superior ao acesso e ao uso da informação (Barreto, 2002).

O compartilhamento das informações como consequência da construção do conhecimento tem um papel importante para as organizações, como se pode perceber nas palavras de Probst et al. (2002): o compartilhamento e a distribuição de conhecimento têm uma posição de destaque na gestão do conhecimento. Elas apoiam fatores competitivos vitais como tempo e qualidade, e possuem alavancagem devido à sua importância para outros aspectos da gestão do conhecimento.

Choo (2003) apresenta aspectos comuns à partilha da informação: as pessoas usam ricos canais de informação em discussões face a face para se concentrar nos problemas, lidar com a incerteza e a indefinição, resolver diferenças e estimular a criatividade. As pessoas precisam de um fluxo contínuo de informações externas para esclarecer ambiguidades, preencher lacunas, atualizar interpretações e obter feedback. Cada um desses aspectos é um objetivo da distribuição da informação (Choo, 2003).

Alcará et al. (2009) apresentam uma pesquisa sobre os fatores que influenciam o compartilhamento da informação. O primeiro é a motivação para o compartilhamento, que pode ser definida como aquilo que impulsiona a pessoa a agir de determinada forma, a ter determinada atitude ou comportamento diante de uma situação. Identificaram-se alguns elementos, como, por exemplo, a confiança, a amizade, a afinidade, a harmonia e a doação, que podem interferir na motivação para o compartilhamento. O segundo são as barreiras no compartilhamento, já que existem fatores que contribuem para retardar e até impedir o processo de compartilhamento da informação. Tais fatores podem ser de ordem estrutural, logística, cultural e psicológica, inerentes aos indivíduos e à própria organização em que atuam, ou podem se referir à falta de confiança no outro. O terceiro é a obrigatoriedade para compartilhar, caracterizada pela busca de equipamentos, laboratórios, resoluções de problemas e conhecimentos de pesquisadores ou especialistas da mesma área. Esse processo, a princípio de natureza formal, pode fortalecer os canais de comunicação informais, ou seja, as relações informais, em que a troca e o compartilhamento de informações e de conhecimento podem ocorrer de forma mais natural. O quarto são as formas e o meio de compartilhamento. Para tanto, é preciso escolher um meio eficaz direto ou indireto. Nos meios diretos, as relações para a obtenção da informação podem acontecer com as pessoas que os próprios pesquisadores conhecem, com os colegas na universidade. No que diz respeito aos meios indiretos, a busca da informação ocorre por meio da literatura, porque as leituras suscitam questões que fazem os pesquisadores buscarem o compartilhamento com o autor, que é, então, procurado tanto por seus pares, quanto pelas pessoas que leram seus artigos ou se interessaram por eles (Alcará et al., 2009).

Tomaél et al. (2005) discutem a questão do compartilhamento em redes. Entendem que as redes sociais são utilizadas pela sociedade para o compartilhamento da informação e do conhecimento, mediante as relações entre seus atores. Nessas redes, cada indivíduo tem sua função e identidade e sua formação ocorrerá de acordo com a temática da organização.

Com o compartilhamento do conhecimento interno nas organizações, foram alcançados diversos resultados, desde o mapeamento do conhecimento, que permite localizar quem produz determinado tipo de conhecimento, até a construção de repositórios de conhecimento, que possibilitam, por meio do conhecimento explicitado, a sua reutilização 
(Schenkel, 2008).

Na perspectiva da organização, o compartilhamento de conhecimento entre seus colaboradores promete muitos benefícios, pois permite que a organização produza conhecimento e experiência passada, responda mais rapidamente aos problemas, desenvolva novas ideias e percepções e evita reinventar a roda ou repetir os erros do passado. Por outro lado, para o indivíduo, a partilha de conhecimento é uma proposta mais controversa. Isso requer tempo e esforço e, muitas vezes, gera preocupação com a perda de conhecimento que foi conquistado de forma dura e dúvida sobre como o conhecimento será recebido e colocado em uso por outras pessoas. Essa tensão na intenção organizacional e ambivalência individual tornam a partilha de conhecimentos um desafio significativo nas organizações, até porque sua dinâmica é jogada para fora do nível individual (Cir \& Choo, 2010).

Dessa forma, Cir e Choo (2010) concluíram que o compartilhamento de conhecimento é volitivo e não pode ser forçado ou obrigatório. Embora as organizações possam deliberar que os funcionários partilhem seu conhecimento, funcionários relutantes sempre encontram maneiras de contornar ou minar o espírito de tais diretivas. Também se descobriu que as percepções individuais sobre custos e benefícios, as preferências pessoais sobre a distribuição de compartilhamento de resultados e a relação estrutural de destinatários de conhecimento têm efeitos sobre o comportamento de compartilhar conhecimentos.

\section{Discussão e considerações}

Atualmente, o principal desafio do gerenciamento dos recursos pesqueiros é conseguir conjugar a necessidade de conservação dos ecossistemas naturais e a exploração racional desses recursos. Neste caso, exploração racional refere-se a buscar melhorias de base ambiental no processo de beneficiamento desses recursos.

Para a realização do gerenciamento dos recursos pesqueiros de forma adequada, com planejamento setorial integrado que possa proporcionar benefícios ambientais, econômicos, sociais e culturais, sem que ocorram danos ambientais, é necessário definir se o alvo é apenas um determinado recurso pesqueiro, cujo potencial de produção se deseja avaliar ou se tal análise precisa ser articulada a uma avaliação ecossistêmica, muito mais complexa, encadeando inúmeras variáveis que permeiam e interferem na capacidade de produzir mais ou menos. Dessa forma, na Figura 3, representa-se um modelo de gestão da informação que pode contribuir para o uso dos recursos pesqueiros com base nos fundamentos conceituais.

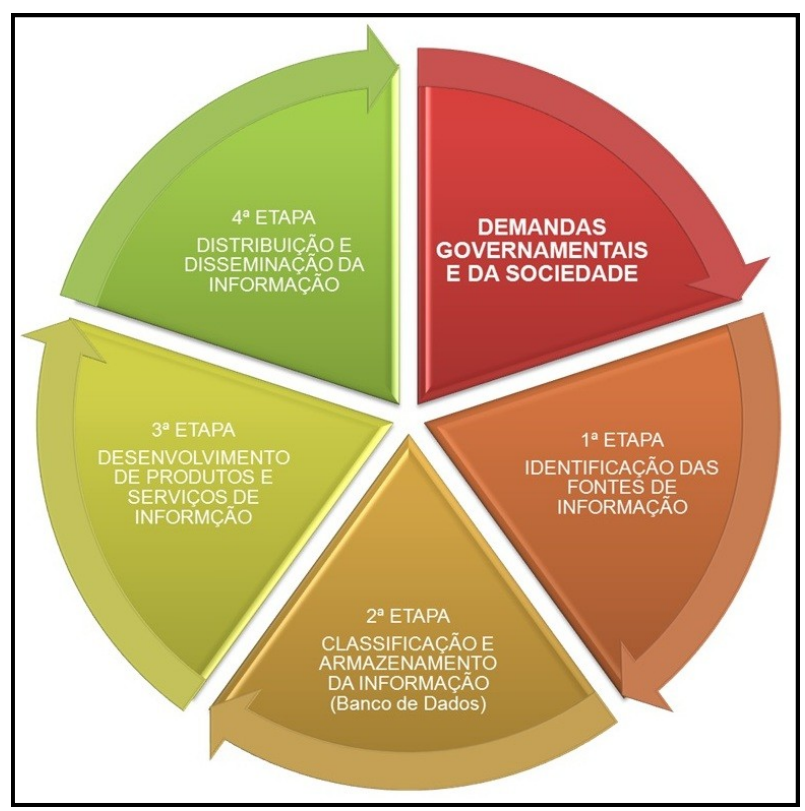

Figura 3. Modelo de gestão da informação para o setor pesqueiro.

Esse modelo é estruturado em forma de processos sequenciais e interativos, composto por quatro etapas, que têm como objetivo o atendimento às demandas tanto governamentais/institucionais como demandas provenientes da sociedade civil organizada.

O ponto de partida desse processo são as demandas governamentais e institucionais IBAMA, ICMBio, Ministério Público da União (MPU), Justiça Federal, Ministério do Meio 
Ambiente (MMA) e Ministério da Pesca e Aquicultura - e/ou as demandas oriundas da sociedade - cidadãos/sociedades civis, federação dos pescadores, colônia de pescadores, sindicatos dos pescadores e armadores, pesquisadores, estudantes de graduação e pós-graduação e ambientalistas, dentre outros.

Na primeira etapa, são identificadas as necessidades e os requisitos de informação, utilizando as fontes de informação disponíveis, tais como: bases de dados, banco de dados, repositórios, bibliografias, catálogos de bibliotecas, anais de encontros científicos, dicionários, glossários, fontes de informações geográficas, guias, informações estatísticas, legislação pesqueira, manuais, metodologia científica, órgãos, centros e institutos de pesquisa, periódicos, projetos e pesquisas em andamento, relatórios técnicos, sistema de mapa de bordo, teses e dissertações.

$\mathrm{Na}$ segunda etapa, essas informações são classificadas e armazenadas (tratamento técnico) utilizando-se um sistema integrado de banco de dados e a biblioteca como gestor local. Ressalta-se a importância de hospedar conteúdos informativos em diversos formatos e mídias (impresso, digital, audiovisual, mapas, dentre outros).

$\mathrm{Na}$ terceira etapa, no desenvolvimento de produtos e serviços de informação, são propostos os seguintes produtos: serviço de atualização de informações ambientais, banco de dados de relatórios de problemas e soluções, mapas, rede de especialistas, release institucional e alerta bibliográfico.

$\mathrm{Na}$ quarta etapa, todas as etapas são integradas e realimentam o sistema, tanto com fluxos internos como externos. Nessa etapa, é distribuída e realizada a difusão da informação por meio de disseminação seletiva da informação interna e externa, uso de mala direta online, divulgação de conteúdo institucional por meio de $e$-mails, página na Internet e fóruns especializados, apresentação de relatórios técnicos e utilização das redes sociais e colaborati- vas para divulgação e promoção.

O resultado esperado é um processo informacional que contribua para a elaboração, a implementação e o controle de ações, para o monitoramento do ambiente interno e externo e para as tomadas de decisão, o que proporciona, assim, um gerenciamento mais adequado no uso dos recursos pesqueiros.

Para sustentar e auxiliar o gerenciamento do uso dos recursos pesqueiros, é importante a existência de uma cadeia de informação organizada, ou seja, a identificação e o conhecimento das fontes de informações biológicas, ambientais e socioeconômicas, incluindo as de produção, que possam, juntas, dar respostas às demandas dos gestores e da sociedade. Tais necessidades envolvem outras questões, como a possibilidade em obter rapidez no compartilhamento das respostas e distribuição e utilização das ferramentas de comunicação e informação (site/portal, e-mail, redes sociais e telecomunicação), ações que, no conjunto, favorecem a agilidade do processo.

Por fim, outra questão importante é a articulação da gestão da informação e dos recursos pesqueiros de forma transparente e multi-institucional, a partir de pescadores (artesanais/industriais), armadores, empresários, pesquisadores, gestores públicos, ambientalistas e várias outras organizações da sociedade e de governo envolvidas com o desenvolvimento social, econômico e ambiental. Essa articulação, como um processo legítimo de geração e distribuição de informação e conhecimento com envolvimento amplo desses atores, legitima, assim, o resultado como algo plural, como uma construção coletiva e colaborativa. Dessa forma, contribuindo por fomentar a proposição de novas demandas de gestão da informação, a partir desses diferentes atores sociais.

\section{Referências}

ABRAHAMSON, D. E. \& J. GOODMANDELAHUNTY. 2013. The impact of organ- 
izational information culture on information use outcomes in policing: an exploratory study. Information Research, 18(4). Disponível em : http:// www.informationr.net/ir/18-4/ paper598.html. Acesso em: 15 maio 2015.

ALCARÁ, A. R., I. G. DI CHIARA, J. L. RODRIGUES, M. I. TOMAÉL, V. C. H. PIEDADE. 2009. Fatores que influenciam o compartilhamento da informação e do conhecimento. Perspect. ciênc. inf., 14(1): 170 -191. Disponível em: http://www.scielo.br/ pdf/pci/v14n1/v14n1a12.pdf. Acesso em: 15 maio 2015 .

ALVARES, L., S. G. BAPTISTA, R. H. ARAÚJO JÚNIOR. 2010. Gestão do conhecimento: categorização conceitual. Em Questão: Revista da Faculdade de Biblioteconomia e Comunicação da UFRGS, 16(2): 235-252. Disponível em: http://seer.ufrgs.br/ EmQuestao/article/view/15124/10437. Acesso em: 13 jul. 2011.

BARRETO, A. A. 2002. A condição da informação. São Paulo em Perspectivas, São Paulo, 16(3):67-74. Disponível em: http:// www.scielo.br/scielo.php?pid=S010288392002000300010\&script $=$ sci $\_$arttext. Acesso em: 15 maio 2015.

CASTELLS, M. 1999. A revolução da tecnologia da informação. In CASTELLS, M. A sociedade em rede: a era da informação, economia, sociedade e cultura. São Paulo, Paz e Terra, cap.1: 49-86.

CHOO, C. W. 2003. A Organização do conhecimento: como as organizações usam a informação para criar significa, construir conhecimento e tomar decisões. Tradução Eliana Rocha. São Paulo, SENAC.

COSTA, M. M. R. D. 2003. Procedimentos para aplicação de mapas semânticos como estratégia para criação do conhecimento organizacional. Florianópolis, SC, 195 p. (Tese de Doutorado em Engenharia de Produção, Universidade Federal de Santa Catarina). Disponível em: https://repositorio.ufsc.br/ x m l u i / b i t s t r e a m / handle/123456789/84904/199734.pdf? sequence $=1 \&$ isAllowed $=\mathrm{y}$. Acesso em: 15 maio 2015.

CYR, S. \& C. W. CHOO. 2010. The individual and social dynamics of knowledge sharing: an exploratory study. Journal of Documentation, 66(6): 824-846. Disponível em: http://choo.ischool.utoronto.ca/FIS/ ResPub/choo jdoc2010.pdf. Acesso em: 15 maio 2015.

DAVENPORT, T. H., D. A. MARCHAND, T. DICKSON . 2004. Dominando a gestão da informação. Porto Alegre, Bookman.

DIEGUES, A. C. S. 2004. A pesca construindo sociedades: leituras em antropologia marítima pesqueira. São Paulo, NUPAUBUSP.

KERR PINHEIRO, M. M. 2010. Processo de transformação das políticas de informação no estado informacional. Tendências da Pesquisa Brasileira em Ciência da Informação, Brasília, 3(1): 113-126. Disponível em: <http://inseer.ibict.br/ancib/ index.php/tpbci/article/view/30/60 $>$. Acesso em: 15 maio 2015 .

LE COADIC, I. F. 2004. A ciência da Informação. Brasília, DF, Briquet de Lemos.

LEITÃO, P. C. C. \& M. E. NASSIF. 2009. Decisões estratégicas e informação: sensemaking organizacional como abordagem alternativa. Estratégia e negócios, Florianópolis, 2(1): 136-157. Disponível em: http:// www.portaldeperiodicos.unisul.br/ index.php/EeN/article/view/55/55. Acesso em: 12 jul. 2011.

LEVY, P. 2001. A conexão planetária: o mercado, o ciberespaço, a consciência. Rio de Janeiro, Ed. 34.

MARCONI, M. A. \& E. M. LAKATOS. 2010. Fundamentos de metodologia científica. 7 . ed. São Paulo, Atlas. 297 p.

MATTELART, A. 2002. História da sociedade da informação. São Paulo, Loyola. 
MOLINA, L. G. 2010. Tecnologia de informação e comunicação para gestão da informação e do conhecimento: proposta de uma estrutura tecnológica aplicada aos portais corporativos. In VALENTIM, M. (Org.). Gestão, mediação e uso da informação. São Paulo: Cultura Acadêmica, 2010. 143-167. Disponível em: http:// www.culturaacademica.com.br/ downloads/\%7BoCD8B066-775C-4CF1$\mathrm{AF} 3 \mathrm{D}-4 \mathrm{~F} 6 \mathrm{C} 764 \mathrm{E} 13 \mathrm{E} 3 \%$ 7D Gestao mediacao-digital.pdf. Acesso em: 13 jul. 2011.

PROBST, G., S. RAUB, K. ROMHARDT. 2002. Gestão do conhecimento: os elementos construtivos do sucesso. Porto Alegre, Bookman.

RODRIGUES, C. 2012. Gestão da informação do Centro de Pesquisa e Gestão de Recursos Pesqueiros do Litoral Sudeste e Sul (CEPSUL): estudo de caso. Florianópolis, SC, 301 p. (Dissertação de Mestrado em Ciência da Informação, Universidade Federal de Santa Catarina). Disponível em: https://repositorio.ufsc.br/bitstream/ handle/123456789/96411/304059.pdf? sequence $=1$. Acesso em: 15 maio 2015.

SCHENKEL, M. B. C. 2008. Compartilhamento do conhecimento científico em instituição estadual de ensino superior: o caso do Centro de Ciências Humanas e da Educação da Udesc. Florianópolis, SC, 134p. (Dissertação de Mestrado em Ciência da Informação, Universidade Federal de Santa Catarina). Disponível em: https:// repositorio.ufsc.br/xmlui/bitstream/ handle/123456789/91642/258965.pdf? sequence $=1$ \&isAllowed $=y$. Acesso em: 15 maio 2015.

SOUZA, I. G. C. O. \& E. N. DUARTE. 2011. Dimensões de um modelo de gestão da informação no campo da Ciência da Informação: uma revelação da produção científica do ENANCIB. Liinc em revista, Rio de Janeiro, 7(1): 152-169. Disponível em: http:// revista.ibict.br/liinc/index.php/liinc/ article/view/389/279. Acesso em: 13 jul. 2011.

SUGAHARA, C. R. \& P. M. JANNUZZI. 2005. Estudo do uso de fontes de informação para inovação tecnológica na indústria brasileira. Ciência da Informação, Brasília, DF, 34(1): 45-56. Disponível em: http:// www.scielo.br/pdf/ci/v34n1/a06v34n1.pdf. Acesso em: 13 jul. 2011.

TOMAÉL, M. I., A. R. ALCARÁ, I. G. DI CHIARA. 2005. Das redes sociais à inovação. Ciência da Informação, Brasília, DF, 34(2): 93-104. Disponível em: http:// www.scielo.br/pdf/ci/v34n2/28559. Acesso em: 15 maio 2015. 